\title{
Association of CYP2D6 metabolizer status with mammographic density change in response to tamoxifen treatment
}

\author{
Jingmei Li ${ }^{1}$, Kamila Czene ${ }^{2}$, Hiltrud Brauch ${ }^{3}$, Werner Schroth ${ }^{3}$, Pilar Saladores ${ }^{3}$, Yi Li $^{1}$, Keith Humphreys ${ }^{2}$ \\ and Per Hall ${ }^{2 *}$
}

\begin{abstract}
Introduction: Not all breast cancer patients respond to tamoxifen treatment, possibly due to genetic predisposition. As tamoxifen-induced reductions in percent mammographic density (PMD) have been linked to the risk and prognosis of breast cancer, we conducted a candidate gene study to investigate the association between germline CYP2D6 polymorphisms and PMD change.

Methods: Baseline and follow-up mammograms were retrieved for 278 tamoxifen-treated subjects with CYP2D6 metabolizer status (extensive (EM), heterozygous extensive/intermediate (hetEM/IM) or poor metabolizer (PM)). Logistic regression analyses were conducted comparing subjects who experienced $>10 \%$ reduction in PMD to those who experienced $\leq 10 \%$ reduction or increase.

Results: After multivariate adjustment, PMD change was found to be significantly associated with the degree of CYP2D6 enzyme functionality (Ptrend $=0.021)$. Compared with $\mathrm{EM}$, hetEM/IM and PM were $72 \%$ ( $95 \%$ confidence interval (CI): 0.10 to 0.79 ) and $71 \%$ (0.03 to 2.62) less likely to experience a $>10 \%$ reduction, respectively.
\end{abstract}

Conclusions: Tamoxifen-induced change in PMD appears to have a genetic component.

\section{Introduction}

Tamoxifen reduces both the risk and recurrence of breast cancer $[1,2]$. It has recently been shown that a decrease in mammographic density predicts response to tamoxifen [3-5]. There may be genetic reasons as to why some women experience a decrease in mammographic density and a dramatic influence on risk and prognosis of breast cancer. While tamoxifen metabolism is complex, it is known that the Cytochrome P450 2D6 (CYP2D6) enzyme is necessary to produce clinically active metabolites - 4-hydroxytamoxifen and endoxifen. It has been suggested that patients with no functional CYP2D6 alleles should be offered alternatives to tamoxifen [6,7]. We thus hypothesize that only women who are able to metabolize tamoxifen would experience a decrease in density and a potential parallel effect on breast cancer risk and prognosis. In this study, we explored the association between

\footnotetext{
* Correspondence: per.hall@ki.se

2Department of Medical Epidemiology and Biostatistics, Karolinska Institutet, Box 281, 171 77, Stockholm, Sweden

Full list of author information is available at the end of the article
}

CYP2D6 metabolizer phenotype and mammographic density change, using breast cancer cases from a populationbased breast cancer case-control study conducted in Sweden between 1993 and 1995 [8-10].

\section{Methods}

\section{Study population}

Subjects were a subset of the CAncer Hormone Replacement Epidemiology in Sweden (CAHRES) study [8]. Briefly, the parent study consisted of women born in Sweden who were 50 to 74 years old at first diagnosis of invasive breast cancer in the Swedish Cancer Register. Approval for the study was given by the ethical review boards in the respective regions in which the subjects were based: Gothenburg, Linköping, Lund, Umeå, Uppsala and at the Karolinska Institute in Stockholm. Subjects are protected by the informed consent process, in which they were told what was collected and repeatedly given the option of declining to participate. All subjects were informed in writing about the study and that participation was voluntary. The participants have all given their

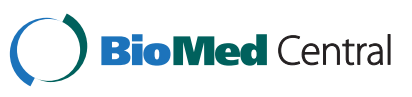


consent in using their DNA for genetic analyses. The process of selection of breast cancer cases included in the current study is summarized in Table 1 .

\section{DNA source and genotyping}

As described previously in [11], DNA was isolated from $3 \mathrm{ml}$ of whole blood with the Wizard Genomic DNA Purification Kit (Promega, Madison, WI, USA) in accordance with the manufacturer's instructions; while DNA from non-malignant cells in paraffin-embedded tissue was extracted by using a standard phenol/chloroform protocol $[11,12]$. Our initial study set in this biomarker study consisted of 710 tamoxifen-treated breast cancer cases genotyped for CYP2D6. DNA from tumor tissue or blood was assayed for polymorphisms associated with reduced ("10, "41) or absent (" $3, "$ " 4 , " 5$)$ enzyme activity, as described previously [7]. The CYP2D6 polymorphisms refer to the CYP Allele Nomenclature Committee (http://www.cypalleles.ki.se) (eTable). Women were classified as having an extensive, heterozygous extensive/ intermediate or poor CYP2D6 metabolism [7].

\section{Mammogram collection and assessment of mammographic density}

Collection of mammograms for the parent study was performed retrospectively. Using national registration numbers [13] that are assigned to all subjects living in Sweden, the current addresses from 1975 to 1995 were obtained for all participants in the parent study through a nationwide population registry. Mammograms were then retrieved from radiology departments conducting screening mammography for those addresses. Mammograms were digitized by the Array 2905HD Laser Film Digitizer, with density resolution set at 12-bit, spatial resolution at $5.0 \mu \mathrm{m}$ and optical density 0 to 4.7 .

Mammographic breast density at baseline $(\leq 1$ year prior to initiation of tamoxifen) and 6 to 36 months after treatment was assessed by a fully automated thresholding

Table 1 Flow of patients through the study (inclusion criteria)

\begin{tabular}{lc}
\hline & $\mathbf{n}$ \\
\hline Genotyped & 710 \\
Overlap with women with mammograms retrieved & 570 \\
Nonmissing date of initiation of tamoxifen therapy & 562 \\
Duration of treatment $\geq 6$ months & 530 \\
Complete set of baseline and follow-up mammograms & 309 \\
Postmenopausal at baseline & 308 \\
Genotyped from blood & 278 \\
Baseline percent mammographic density (PMD) $\geq 10 \%$ & 186 \\
\hline
\end{tabular}

method [14] and expressed as a percentage of the total breast area (percent mammographic density, PMD). The observed correlation between PMD measured by the current gold standard, a computer-assisted semi-automatic thresholding method named Cumulus, and the automated thresholding method used here was $(r=0.88 ; 95 \% \mathrm{CI}, 0.87$ to 0.89 ) in an external test set [14]. For women with multiple mammograms available within the study period, the image taken closest to the second year after treatment start was selected for follow-up (median time from initiation = 1.96 , interquartile range $=0.50$ ).

Table 2 Description of selected characteristics in subjects

\begin{tabular}{|c|c|c|c|}
\hline & $\begin{array}{c}\text { PMD } \\
\text { reduction } \\
\leq 10 \% \\
n=247\end{array}$ & $\begin{array}{c}\text { PMD } \\
\text { reduction } \\
>10 \% \\
n=31\end{array}$ & $P$ \\
\hline \multicolumn{4}{|l|}{ Baseline characteristics } \\
\hline Age (years) & $63.8 \pm 6.2$ & $61.5 \pm 5.9$ & 0.05 \\
\hline $\mathrm{BMI}\left(\mathrm{kg} / \mathrm{m}^{2}\right)$ & $25.4 \pm 3.7$ & $24.1 \pm 4$ & 0.02 \\
\hline HRT ever & & & 0.10 \\
\hline No & $106(42.9)$ & $8(25.8)$ & \\
\hline Yes & $141(57.1)$ & $23(74.2)$ & \\
\hline Baseline PMD & $14.7 \pm 9.5$ & $32 \pm 9.1$ & $<0.001$ \\
\hline $\begin{array}{l}\text { Time between } \\
\text { mammograms (years) }\end{array}$ & $1.9 \pm 0.6$ & $2.0 \pm 0.5$ & 0.30 \\
\hline \multicolumn{4}{|l|}{ Tumor characteristics } \\
\hline ER status & & & 0.15 \\
\hline Positive & $167(67.6)$ & $26(83.9)$ & \\
\hline Negative & $29(11.7)$ & $1(3.2)$ & \\
\hline Missing & $51(20.6)$ & $4(12.9)$ & \\
\hline \multicolumn{4}{|l|}{ Treatment } \\
\hline Chemotherapy & & & 0.48 \\
\hline No & $236(95.5)$ & $31(100)$ & \\
\hline Yes & $11(4.5)$ & $0(0)$ & \\
\hline Radiotherapy & & & 0.60 \\
\hline No & $159(64.4)$ & $22(71)$ & \\
\hline Yes & 88 (35.6) & $9(29)$ & \\
\hline \multicolumn{4}{|l|}{ Tamoxifen (mg) } \\
\hline 20 & $137(55.5)$ & $13(41.9)$ & 0.47 \\
\hline 40 & $50(20.2)$ & $9(29.0)$ & \\
\hline 20 and 40 & $57(23.1)$ & $9(29.0)$ & \\
\hline${ }^{*}$ Others & $3(1.2)$ & $0(0)$ & \\
\hline
\end{tabular}

Description of selected characteristics in subjects with less than or greater than a $10 \%$ percent mammographic density (PMD) reduction, with $P$ values for association. Categorical variables (frequencies (\%)) were assessed for association using chi-squared tests, while continuous variables (means \pm standard deviation (SD)) were assessed using Kruskal-Wallis tests. ${ }^{*}$ One woman was prescribed an unknown dose of tamoxifen. Two women were prescribed tamoxifen citrate and two were prescribed toremifene, a chlorinated derivative of tamoxifen. $H R T$, hormone replacement therapy; BMI, body mass index; ER, estrogen receptor. 


\section{Statistical analysis}

Our primary endpoint was change in PMD between followup and baseline. As change in PMD and absolute mammographic dense area were highly correlated (Spearman's rho correlation coefficient $=0.89$ ) in our data, we limited our association analysis CYP2D6 metabolizer status and mammographic density to PMD change. To identify other covariates (confounders) for PMD change, we explored the role of baseline PMD, age at diagnosis (years), body mass index (BMI) $\left(\mathrm{kg} / \mathrm{m}^{2}\right)$ at baseline, time difference between baseline and follow-up mammograms (years), history of ever hormone replacement therapy and estrogen receptor (ER) (negative, positive or missing) status using chisquared and Kruskal-Wallis tests. As there might be mammographic changes caused by other cancer treatments, we also assessed chemotherapy [15] and ever radiotherapy $[16,17]$ as potential confounders. Variables which were found to be significantly associated with PMD change were retained in the final logistic regression model and adjusted for. Linear regression models were initially applied to examine PMD change as a continuous variable. The Wald test was used to determine the statistical significance of an overall linear trend for the association between CYP2D6 metabolizer status, treated as a semi-continuous variable, and binary PMD change $(P$ trend). For univariate analyses involving PMD change (continuous variable), baseline and follow-up PMD, the nonparametric Cuzick's test for trend was also used (Pnptrend). The goodness-of-fit and proportion of total variance explained by linear regression models with more than one predictor variable were assessed using adjusted $\mathrm{R}^{2}$ statistics. Odds ratios (ORs) and 95\% confidence intervals (CIs) (lower bound of a 95\% confidence interval (L95), upper bound of a 95\% confidence interval (U95)) were estimated by applying a logistic regression model, using the group with $10 \%$ reduction as a reference. Goodness-of-fit of logistic regression models was tested using the Hosmer-Lemeshow test. A $P$ value of $\leq 0.05$ was considered statistically significant. All statistical tests were two-sided. Statistical analyses were performed using $\mathrm{R}$ (version 2.15.1) [18].

The dataset consisted of 308 subjects who were postmenopausal at baseline and who underwent treatment for $\geq 6$ months. Genetic variants in CYP2D6 assayed from tumor-derived DNA are at risk of misclassification due to loss of heterozygosity $[19,20]$, hence we restricted our analysis to 278 patients with genotypes derived from blood.

\section{Results and discussion}

Table 2 shows that PMD change as a binary variable was significantly associated with age $(P=0.05)$ and BMI $(P=$ $0.02)$ at baseline, and strongly associated with baseline PMD $(P<0.001)$, results which are corroborated by previous findings [21,22]. Both age and BMI at baseline were also found to be highly significantly associated with baseline PMD $(P<0.001)$.

Table 3 Results of linear regression analyses

\begin{tabular}{|c|c|c|c|c|c|c|c|c|c|c|}
\hline & \multirow[b]{2}{*}{$\mathrm{n}$} & \multicolumn{5}{|c|}{ Univariate } & \multicolumn{4}{|c|}{ Adjusted } \\
\hline & & Beta & SE & Pwald & Ptrend & Pnptrend & Beta & SE & Pwald & Ptrend \\
\hline \multicolumn{11}{|c|}{ PMD change (continuous)* } \\
\hline EM & 122 & 0.00 & \multicolumn{2}{|c|}{ Reference } & 0.053 & 0.074 & 0.00 & \multicolumn{2}{|c|}{ Reference } & 0.11 \\
\hline hetEM/IM & 136 & 1.47 & 0.78 & 0.06 & & & 0.87 & 0.67 & 0.19 & \\
\hline PM & 20 & 1.89 & 1.51 & 0.21 & & & 1.61 & 1.29 & 0.21 & \\
\hline Adjusted $\mathrm{R}^{2}$ & & & & & 0.010 & & & & & 0.281 \\
\hline \multicolumn{11}{|l|}{ Baseline PMDt } \\
\hline EM & 122 & 0.00 & \multicolumn{2}{|c|}{ Reference } & 0.389 & 0.301 & 0.00 & \multicolumn{2}{|c|}{ Reference } & 0.771 \\
\hline hetEM/IM & 136 & -0.24 & 0.17 & 0.16 & & & -0.17 & 0.15 & 0.29 & \\
\hline PM & 20 & 0.00 & 0.33 & 1.00 & & & 0.11 & 0.30 & 0.72 & \\
\hline Adjusted $\mathrm{R}^{2}$ & & & & & 0.001 & & & & & 0.162 \\
\hline \multicolumn{11}{|c|}{ Follow-up PMDt } \\
\hline EM & 122 & 0.00 & \multicolumn{2}{|c|}{ Reference } & 0.831 & 0.999 & 0.00 & \multicolumn{2}{|c|}{ Reference } & 0.413 \\
\hline hetEM/IM & 136 & -0.07 & 0.15 & 0.64 & & & -0.02 & 0.14 & 0.90 & \\
\hline PM & 20 & 0.23 & 0.30 & 0.44 & & & 0.31 & 0.28 & 0.27 & \\
\hline Adjusted $\mathrm{R}^{2}$ & & & & & -0.003 & & & & & 0.100 \\
\hline
\end{tabular}

Results of linear regression analyses treating the absolute difference between follow-up and baseline values in percent mammographic density (PMD) as a continuous variable, and PMD at baseline and follow-up separately. PMD at baseline or follow-up was square-root transformed. *Adjusted for baseline percent mammographic density (PMD), age at baseline (years), and body mass index at baseline $\left(\mathrm{kg} / \mathrm{m}^{2}\right)$. + Adjusted for all of the above except for baseline PMD. SE, standard error; Pwald, $P$ value from Wald tests; Ptrend, $P$ value from Wald tests treating genotypes $(0,1,2)$ as a continuous variable; Pnptrend, $P$ value from Cuzick's test for trend; EM, extensive metabolizer; hetEM/IM, heterozygous extensive/intermediate; PM, poor metabolizer; adjusted $\mathrm{R}^{2}$, adjusted $\mathrm{R}^{2}$ statistic. 
Results of linear regression analyses treating PMD change as a continuous variable revealed a nonsignificant trend of less PMD decline with reduced CYP2D6 functionality $(P=0.11$, Table 3$)$. The variance of PMD change as a quantitative trait explained by CYP2D6 metabolizer status was modest (approximately 1.0\%), although in keeping with most genetic studies of traits assaying common genetic variants of low penetrance [23]. CYP2D6 metabolizer status was not associated with either baseline or follow-up mammogram alone (Table 3), which agrees with previous findings that PMD does not predict survival when considered at single time points [5,24].

As the use of categorical cutoff points allows for an easy application and interpretation, we $a$ priori specified and dichotomized the difference between PMD at follow-up and baseline into $\leq 10 \%$ reduction and $>10 \%$ reduction. A PMD change of $10 \%$ has been reported to be the minimum difference that could be reproducibly detected by visual assessment $[3,4]$. Four examples of approximately 10\% PMD reduction are shown in Figure 1.

When using this cutoff, our data is consistent with the hypothesis that women with reduced CYP2D6 function are less likely to experience a decline in PMD. PMD change during tamoxifen therapy was found to be significantly associated with the degree of functionality of CYP2D6 (Ptrend $=0.020$, Table 4). Compared with women who were extensive metabolizers of tamoxifen, intermediate and poor metabolizers were $72 \%$ (95\% CI: 0.10 to 0.79 ) and $71 \%$ (0.03 to 2.62 ) less likely to experience a $>10 \%$ reduction, respectively. As it is difficult for women with low baseline PMD to experience a $>10 \%$ PMD change, we repeated the analyses for a subgroup of women with baseline PMD $\geq 10 \%(n=186)$. The significant association between CYP2D6 metabolizer status and PMD change persisted (Ptrend $=0.021$, Table 4). Further adjustment of other potential confounders did not change the estimates appreciably (data not shown). Given the current discussion on genotype-driven tamoxifen dosing $[25,26]$, we further adjusted for drug dosage to account for effective therapeutic metabolite ranges of different CYP2D6 metabolizer status, but did not observe an appreciable change in the results (data not shown). The boxplot in Figure 2 shows graphically that PMD reduction was weaker with genetic CYP2D6 deficiency. It has recently been shown that mammographic density at time of breast cancer diagnosis did not influence breast cancer prognosis [5,24], but while mammographic density did not have a bearing on

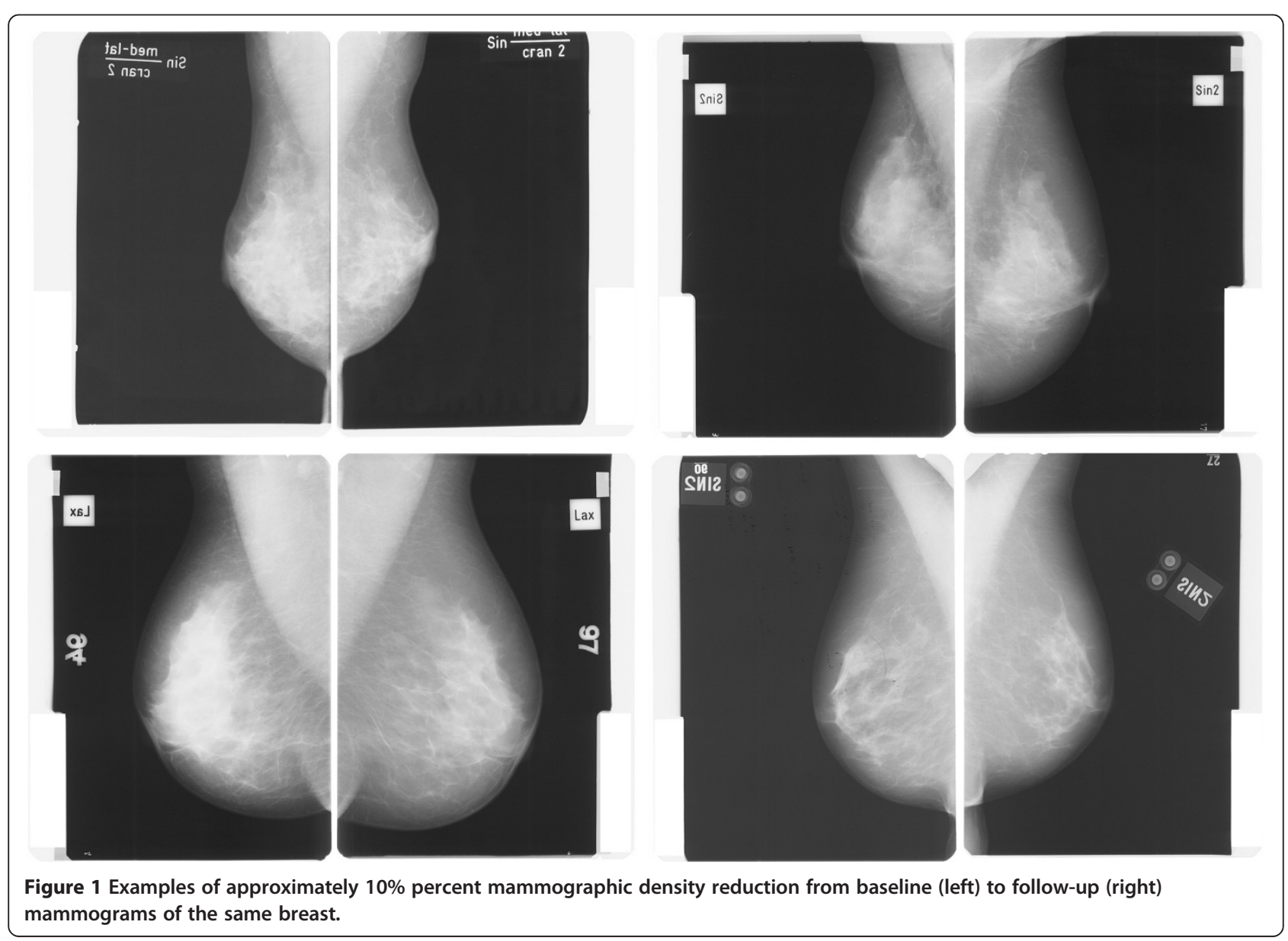


Table 4 Results of tests of association between CYP2D6 metabolizer variants and change in percent mammographic density

\begin{tabular}{|c|c|c|c|c|c|c|c|c|c|c|}
\hline & \multicolumn{2}{|c|}{ PMD reduction } & \multicolumn{4}{|c|}{ Univariate } & \multicolumn{4}{|c|}{ Adjusted } \\
\hline & $\leq 10 \%$ & $>10 \%$ & OR & L95 & U95 & Ptrend & OR & L95 & U95 & Ptrend \\
\hline \multicolumn{11}{|c|}{ + Genotyped from whole blood } \\
\hline EM & 101 & 21 & 1.00 & \multicolumn{2}{|c|}{ Reference } & 0.009 & 1.00 & \multicolumn{2}{|c|}{ Reference } & 0.020 \\
\hline hetEM/IM & 127 & 9 & 0.34 & 0.15 & 0.78 & & 0.28 & 0.10 & 0.79 & \\
\hline PM & 19 & 1 & 0.25 & 0.03 & 2.00 & & 0.29 & 0.03 & 2.62 & \\
\hline \multicolumn{11}{|l|}{$n=278$} \\
\hline GOF & & & & & & & & & & 0.928 \\
\hline \multicolumn{11}{|c|}{ + Genotyped from whole blood } \\
\hline \multicolumn{11}{|c|}{ + Baseline PMD $\geq 10 \%$} \\
\hline EM & 63 & 21 & 1.00 & \multicolumn{2}{|c|}{ Reference } & 0.010 & 1.00 & \multicolumn{2}{|c|}{ Reference } & 0.021 \\
\hline hetEM/IM & 79 & 9 & 0.34 & 0.15 & 0.80 & & 0.29 & 0.11 & 0.81 & \\
\hline PM & 13 & 1 & 0.23 & 0.03 & 1.87 & & 0.29 & 0.03 & 2.57 & \\
\hline \multicolumn{11}{|l|}{$\mathrm{n}=186$} \\
\hline GOF & & & & & & & & & & 0.609 \\
\hline
\end{tabular}

Results of tests of association between CYP2D6 metabolizer variants and change in percent mammographic density (PMD) in subjects treated with tamoxifen for at least six months. Mammograms were taken $\leq 1$ year prior to initiation of tamoxifen, up to three years after treatment. The mammogram taken closest to the second year after tamoxifen treatment was selected for follow-up. Odds ratios (ODs) and 95\% confidence intervals (Cls) (lower bound of a 95\% confidence interval (L95), upper bound of a 95\% confidence interval (U95)) were estimated by applying a logistic regression model, using the group with $10 \%$ reduction as a reference. Analyses were adjusted for baseline PMD, age at diagnosis (years), and body mass index $\left(\mathrm{kg} / \mathrm{m}^{2}\right)$ at baseline. The Wald test was used to determine the statistical significance of an overall linear trend for the association between CYP2D6 metabolizer status, treated as a semi-continuous variable, and PMD change (Ptrend). All statistical tests were two-sided. Statistical analyses were performed using R (version 2.15.1) [18]. EM, extensive metabolizer; hetEM/IM, heterozygous extensive/intermediate; PM, poor metabolizer; GOF, $P$ value for Hosmer-Lemeshow goodness-of-fit test for logistic regression.

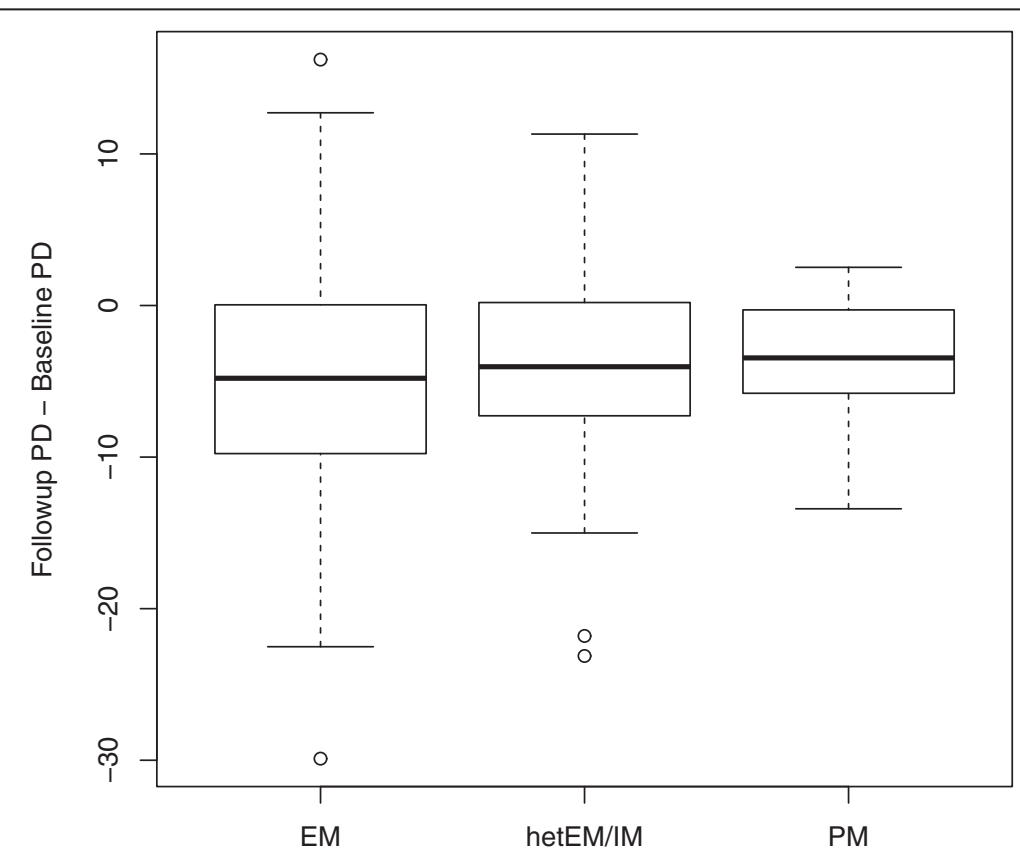

Figure 2 Boxplot of percent mammographic density (PMD) change by CYP2D6 metabolizer status. Boxplot of percent mammographic density (PMD) change by CYP2D6 metabolizer status for subjects genotyped from whole blood and with baseline PMD $\geq 10 \%(n=186)$. The maximum length of each whisker is 1.5 times the interquartile range. EM, extensive metabolizer; hetEM/IM, heterozygous extensive/intermediate; PM, poor metabolizer. 
survival when considered singly at snapshot time points, we reported that a pronounced decrease in mammographic density between baseline and follow-up mammograms following tamoxifen treatment was found to significantly reduced the risk of dying from breast cancer in a previous study [5]. An independent study in an Asian population also showed that mammographic density change during short-term use of adjuvant endocrine therapy was also found to be a significant predictor of longterm recurrence in women with ER-positive breast cancer [3]. It is conceivable that the association between PMD change and breast cancer survival in patients treated with tamoxifen could be explained by differences in compliance or in this case, an inherited response to treatment (for example due to genetic variation in the CYP2D6 gene).

Nonetheless, two large trials have previously reported a null association between CYP2D6 genotype and breast cancer outcome $[27,28]$, which appears to contradict our findings. The validity of the two studies, however, has been questioned due to the quality of genotyping on the basis of massive departures from Hardy-Weinberg equilibrium and the use of tumor tissue [29]. In this study, we have addressed the concerns and restricted our analysis to germline DNA extracted from blood. The individual genotype counts of CYP2D6 metabolizer status were also presented in the results.

To the best of our knowledge, this is the first time that CYP2D6 has been shown to influence PMD change. A major strength is the comprehensive assembly of various datasets, which helped to give rise to a new mechanistic insight on a putative relationship between active metabolites, as predicted by CY2D6 metabolizer status, and local morphological changes. Using a fully automatic thresholding method to measure PMD on serial mammograms adds to the strength of our study as intra- and interreader variability was substantially reduced. The method produces one reproducible reading per mammogram; unlike other user-dependent methods, in which readings can vary when a mammogram is reread by the same user, or read by another user. However, due to a limitation in size of the study, validation of our findings in an independent dataset is of critical importance. A lack of adequate data prevents the ruling out of the impact of CYP2D6 inhibitors on the results.

\section{Conclusions}

In conclusion, our exploratory study has yielded preliminary evidence to show that there is a significant association between CYP2D6 metabolizer status and PMD change, suggesting that the capacity for PMD change may be inherited. Although the sample size is limited, our finding may still be clinically important and warrant further consideration. The question of whether CYP2D6 could be used as a risk or prognostic marker for mammographic density changes in response to tamoxifen treatment will require larger prospective studies.

\section{Abbreviations}

BMI: Body mass index; CAHRES: Cancer hormone replacement epidemiology in Sweden; Cl: Confidence interval; CYP2D6: cytochrome P450 2D6;

EM: Extensive metabolizer; ER: Estrogen receptor; hetEM/IM: Extensive/ intermediate metabolizer; L95: Lower bound of a 95\% confidence interval; OR: Odds ratio; PM: Poor metabolizer; PMD: Percent mammographic density; SD: Standard deviation; U95: Upper bound of a 95\% confidence interval.

\section{Competing interests}

The authors declare that they have no competing interests.

\section{Authors' contributions}

$\mathrm{PH}$ conceived of the study. PH, KC, KH, YL and JL participated in the design of the study and performed the statistical analysis. PH, KC, KH, JL, WS, HB and PS participated in its design and coordination and helped to draft the manuscript. All authors read and approved the final manuscript.

\section{Grant support}

This work was supported by the Märit and Hans Rausing's Initiative Against Breast Cancer, the W81XWH-05-1-0314 Innovator Award (US Department of Defense Breast Cancer Research Program, Office of the Congressionally Directed Medical Research Programs), and the Robert Bosch Foundation Stuttgart. PS was supported by the 7FP EU Marie Curie Initial Training Network 'FightingDrugFailure' (GA 238132). JL was supported by the $2^{\text {nd }}$ Joint Council Office Career Development Award (13302EG065). KH was supported by the Swedish Research Council (523-2006-972) and the Swedish e-Science Research Centre. KC was supported by the Swedish Cancer Society (5128-B07-01PAF)

\section{Author details}

${ }^{1}$ Human Genetics, Genome Institute of Singapore, 60 Biopolis Street, 138672, Singapore, Singapore. ${ }^{2}$ Department of Medical Epidemiology and Biostatistics, Karolinska Institutet, Box 281, 171 77, Stockholm, Sweden. ${ }^{3}$ Dr. Margarete Fischer-Bosch Institute of Clinical Pharmacology and University of Tuebingen, Auerbachstr. 112, 70376, Stuttgart, Germany.

Received: 26 June 2013 Accepted: 17 September 2013 Published: 3 October 2013

\section{References}

1. Cuzick J, Forbes JF, Sestak I, Cawthorn S, Hamed H, Holli K, Howell A: Long-term results of tamoxifen prophylaxis for breast cancer - 96-month follow-up of the randomized IBIS-I trial. J Natl Cancer Inst 2007, 99:272-282.

2. Davies C, Godwin J, Gray R, Clarke M, Cutter D, Darby S, McGale P, Pan HC, Taylor C, Wang YC, Dowsett M, Ingle J, Peto R: Relevance of breast cancer hormone receptors and other factors to the efficacy of adjuvant tamoxifen: patient-level meta-analysis of randomised trials. Lancet 2011, 378:771-784.

3. Kim J, Han W, Moon HG, Ahn SK, Shin HC, You JM, Han SW, Im SA, Kim TY, Koo HR, Chang JM, Cho N, Moon WK, Noh DY: Breast density change as a predictive surrogate for response to adjuvant endocrine therapy in hormone receptor positive breast cancer. Breast Cancer Res 2012, 14:R102.

4. Cuzick J, Warwick J, Pinney E, Duffy SW, Cawthorn S, Howell A, Forbes JF, Warren RM: Tamoxifen-induced reduction in mammographic density and breast cancer risk reduction: a nested case-control study. J Nat/ Cancer Inst 2011, 103:744-752.

5. Li J, Humphreys K, Eriksson L, Edgren G, Czene K, Hall P: Mammographic density reduction is a prognostic marker of response to adjuvant tamoxifen therapy in postmenopausal patients with breast cancer. J Clin Oncol 2013, 31:2249-2256.

6. Goetz MP, Kamal A, Ames MM: Tamoxifen pharmacogenomics: the role of CYP2D6 as a predictor of drug response. Clin Pharmacol Ther 2008 83:160-166

7. Schroth W, Goetz MP, Hamann U, Fasching PA, Schmidt M, Winter S, Fritz P, Simon W, Suman VJ, Ames MM, Safgren SL, Kuffel MJ, Ulmer HU, Boländer J, Strick R, Beckmann MW, Koelbl H, Weinshilboum RM, Ingle JN, Eichelbaum M, Schwab M, Brauch H: Association between CYP2D6 polymorphisms 
and outcomes among women with early stage breast cancer treated with tamoxifen. JAMA 2009, 302:1429-1436.

8. Magnusson C, Baron J, Persson I, Wolk A, Bergstrom R, Trichopoulos D, Adami HO: Body size in different periods of life and breast cancer risk in post-menopausal women. Int J Cancer 1998, 76:29-34

9. Magnusson C, Baron JA, Correia N, Bergstrom R, Adami HO, Persson I: Breast-cancer risk following long-term oestrogen- and oestrogenprogestin-replacement therapy. Int J Cancer 1999, 81:339-344.

10. Magnusson CM, Persson IR, Baron JA, Ekbom A, Bergstrom R, Adami HO: The role of reproductive factors and use of oral contraceptives in the aetiology of breast cancer in women aged 50 to 74 years. Int J Cancer 1999, 80:231-236.

11. Wedren S, Lovmar L, Humphreys K, Magnusson C, Melhus H, Syvanen AC, Kindmark A, Landegren U, Fermer ML, Stiger F, Persson I, Baron J,

Weiderpass E: Oestrogen receptor alpha gene haplotype and postmenopausal breast cancer risk: a case control study. Breast Cancer Res 2004, 6:R437-R449.

12. Isola J, DeVries S, Chu L, Ghazvini S, Waldman F: Analysis of changes in DNA sequence copy number by comparative genomic hybridization in archival paraffin-embedded tumor samples. Am J Pathol 1994, 145:1301-1308.

13. Ludvigsson JF, Otterblad-Olausson P, Pettersson BU, Ekbom A: The Swedish personal identity number: possibilities and pitfalls in healthcare and medical research. Eur J Epidemiol 2009, 24:659-667.

14. Li J, Szekely L, Eriksson L, Heddson B, Sundbom A, Czene K, Hall P, Humphreys K: High-throughput mammographic-density measurement: a tool for risk prediction of breast cancer. Breast Cancer Res 2012, 14:R114.

15. Chen JH, Nie K, Bahri S, Hsu CC, Hsu FT, Shih HN, Lin M, Nalcioglu O, Su MY: Decrease in breast density in the contralateral normal breast of patients receiving neoadjuvant chemotherapy: MR imaging evaluation. Radiology 2010, 255:44-52.

16. Buckley JH, Roebuck EJ: Mammographic changes following radiotherapy. Br J Radiol 1986, 59:337-344.

17. Kuzmiak CM, Zeng D, Cole E, Pisano ED: Mammographic findings of partial breast irradiation. Acad Radiol 2009, 16:819-825.

18. R Development Core Team: $R$ : A language and environment for statistical computing. Vienna, Austria: R Foundation for Statistical Computing; 2008

19. Osborne RJ, Hamshere MG: A genome-wide map showing common regions of loss of heterozygosity/allelic imbalance in breast cancer. Cancer Res 2000, 60:3706-3712.

20. Nakamura Y, Ratain MJ, Cox NJ, McLeod HL, Kroetz DL, Flockhart DA: Re: CYP2D6 genotype and tamoxifen response in postmenopausal women with endocrine-responsive breast cancer: the breast international group 1-98 trial. J Natl Cancer Inst 2012, 104:1266-1268.

21. Kelemen LE, Pankratz VS, Sellers TA, Brandt KR, Wang A, Janney C, Fredericksen ZS, Cerhan JR, Vachon CM: Age-specific trends in mammographic density: the Minnesota breast cancer family study. Am J Epidemio/ 2008, 167:1027-1036

22. Maskarinec G, Pagano I, Lurie G, Kolonel LN: A longitudinal investigation of mammographic density: the multiethnic cohort. Cancer Epidemiol Biomarkers Prev 2006, 15:732-739.

23. Lindstrom S, Vachon CM, Li J, Varghese J, Thompson D, Warren R, Brown J, Leyland J, Audley T, Wareham NJ, Loos RJ, Paterson AD, Rommens J, Waggott D, Martin LJ, Scott CG, Pankratz VS, Hankinson SE, Hazra A, Hunter DJ, Hopper JL, Southey MC, Chanock SJ, Silva Idos S, Liu J, Eriksson L, Couch FJ, Stone J, Apicella C, Czene K, et al: Common variants in ZNF365 are associated with both mammographic density and breast cancer risk. Nat Genet 2011, 43:185-187.

24. Gierach GL, Ichikawa L, Kerlikowske K, Brinton LA, Farhat GN, Vacek PM, Weaver DL, Schairer C, Taplin SH, Sherman ME: Relationship between mammographic density and breast cancer death in the Breast Cancer Surveillance Consortium. J Natl Cancer Inst 2012, 104:1218-1227.

25. Irvin WJ Jr, Walko CM, Weck KE, Ibrahim JG, Chiu WK, Dees EC, Moore SG, Olajide OA, Graham ML, Canale ST, Raab RE, Corso SW, Peppercorn JM Anderson SM, Friedman KJ, Ogburn ET, Desta Z, Flockhart DA, McLeod HL, Evans JP, Carey LA: Genotype-guided tamoxifen dosing increases active metabolite exposure in women with reduced CYP2D6 metabolism: a multicenter study. J Clin Oncol 2011, 29:3232-3239.

26. Barginear MF, Jaremko M, Peter I, Yu C, Kasai Y, Kemeny M, Raptis G, Desnick RJ: Increasing tamoxifen dose in breast cancer patients based on CYP2D6 genotypes and endoxifen levels: effect on active metabolite isomers and the antiestrogenic activity score. Clin Pharmacol Ther 2011, 90:605-611.

27. Rae JM, Drury S, Hayes DF, Stearns V, Thibert JN, Haynes BP, Salter J, Sestak I, Cuzick J, Dowsett M: CYP2D6 and UGT2B7 genotype and risk of recurrence in tamoxifen-treated breast cancer patients. $J$ Natl Cancer Inst 2012, 104:452-460.

28. Regan MM, Leyland-Jones B, Bouzyk M, Pagani O, Tang W, Kammler R, Dell'orto P, Biasi MO, Thurlimann B, Lyng MB, Ditzel HJ, Neven P, Debled M, Maibach R, Price KN, Gelber RD, Coates AS, Goldhirsch A, Rae JM, Viale G: CYP2D6 genotype and tamoxifen response in postmenopausal women with endocrine-responsive breast cancer: the breast international group 1-98 Trial. J Natl Cancer Inst 2012, 104:441-451.

29. Brauch H, Schroth W, Goetz MP, Murdter TE, Winter S, Ingle JN, Schwab M, Eichelbaum M: Tamoxifen use in postmenopausal breast cancer: CYP2D6 matters. J Clin Oncol 2013, 31:176-180.

doi: $10.1186 / \mathrm{bcr} 3495$

Cite this article as: Li et al:: Association of CYP2D6 metabolizer status with mammographic density change in response to tamoxifen treatment. Breast Cancer Research 2013 15:R93.

\section{Submit your next manuscript to BioMed Central and take full advantage of:}

- Convenient online submission

- Thorough peer review

- No space constraints or color figure charges

- Immediate publication on acceptance

- Inclusion in PubMed, CAS, Scopus and Google Scholar

- Research which is freely available for redistribution

Submit your manuscript at www.biomedcentral.com/submit
C) Biomed Central 